\title{
Surgical Organ or Space
}

National Cancer Institute

\section{Source}

National Cancer Institute. Surgical Organ or Space. NCI Thesaurus. Code C112022.

Any part of the anatomy, other than the incision, which was opened or manipulated during an operation. 